\title{
Lung volume reduction surgery since the National Emphysema Treatment Trial: Study of Society of Thoracic Surgeons Database
}

\author{
Marquita R. Decker, MD, MPH, ${ }^{\mathrm{a}}$ Glen E. Leverson, $\mathrm{PhD},{ }^{\mathrm{a}}$ Wassim Abi Jaoude, $\mathrm{MD},{ }^{\mathrm{b}}$ and \\ James D. Maloney, MD ${ }^{\mathrm{a}, \mathrm{b}}$
}

Objectives: The National Emphysema Treatment Trial demonstrated that lung volume reduction surgery is an effective treatment for emphysema in select patients. With chronic lower respiratory disease being the third leading cause of death in the United States, this study sought to assess practice patterns and outcomes for lung volume reduction surgery on a national level since the National Emphysema Treatment Trial.

\begin{abstract}
Methods: Aggregate statistics on lung volume reduction surgery reported in the Society of Thoracic Surgeons Database from January 2003 to June 2011 were analyzed to assess procedure volume, preoperative and operative characteristics, and outcomes. Comparisons with published data from the National Emphysema Treatment Trial were made using chi-square and 2 -sided $t$ tests.
\end{abstract}

Results: In 8.5 years, 538 patients underwent lung volume reduction surgery, with 20 to 118 cases reported in the Society of Thoracic Surgeons Database per year. When compared with subjects in the National Emphysema Treatment Trial, subjects in the Society of Thoracic Surgeons Database were younger $(P<.001)$, a larger proportion underwent the procedure thoracoscopically $(P<.001)$, and forced expiratory volume in 1 second was $31 \%$ versus $28 \%$ of predicted $(P<.001)$. When mortality was compared between subjects in the Society of Thoracic Surgeons Database and all subjects in the National Emphysema Treatment Trial randomized to surgery, there were no significant differences. However, mortality was 3\% higher in subjects in the Society of Thoracic Surgeons Database when compared with the non-high-risk National Emphysema Treatment Trial subset $(P=.005)$.

Conclusions: This study demonstrates the importance of patient selection and the need to develop consensus on appropriate benchmarks for mortality rates after lung volume reduction surgery. It underscores the need for dedicated centers to increasingly address the heavy burden of chronic lower respiratory disease in the United States in a multidisciplinary fashion, particularly for preoperative evaluation and postoperative management of emphysema. (J Thorac Cardiovasc Surg 2014;148:2651-8)

\section{Supplemental material is available online.}

Chronic lower respiratory disease is the third leading cause of death in the United States, ${ }^{1}$ with chronic obstructive pulmonary disease (COPD) taking approximately 126,000 lives every year. ${ }^{2}$ At least one third of these COPD cases are related to a diagnosis of emphysema. ${ }^{3}$ Contemporary treatment options for emphysema

\footnotetext{
From the Wisconsin Surgical Outcomes Research Program, ${ }^{a}$ Department of Surgery, University of Wisconsin, Madison, Wis; and Division of Cardiothoracic Surgery, ${ }^{b}$ Department of Surgery, University of Wisconsin, Madison, Wis.

Funding: The work of Dr Decker was supported by a National Institutes of Health Surgical Oncology Research Training Grant T32CA090217.

Disclosures: Authors have nothing to disclose with regard to commercial support.

Read in part at the CHEST 2012 Scientific Program, October 20-25, 2012, Atlanta, Georgia.

Received for publication June 11, 2013; revisions received Oct 12, 2013; accepted for publication Feb 3, 2014; available ahead of print March 14, 2014.

Address for reprints: James D. Maloney, MD, 600 Highland Ave, H4/358 Clinical Science Center, Madison, WI (E-mail: maloney@surgery.wisc.edu). $0022-5223 / \$ 36.00$

Copyright (C) 2014 by The American Association for Thoracic Surgery http://dx.doi.org/10.1016/j.jtcvs.2014.02.005
}

include oxygen therapy, beta agonists and anticholinergics, oral and inhaled steroids, pulmonary rehabilitation, lung transplantation, experimental endobronchial therapies, and lung volume reduction surgery (LVRS). LVRS has been reported to improve long-term survival and quality of life in appropriately selected patients with emphysema, ${ }^{4-9}$ but LVRS practice patterns and outcomes have not since been evaluated nationally, outside of a clinical trial.

The National Emphysema Treatment Trial (NETT), ${ }^{4,5}$ which first published results in 2003, randomized 1218 patients with emphysema to LVRS or best medical therapy and examined the primary end points of survival and maximal exercise performance, with secondary end points of pulmonary function, patient symptom severity, and quality of life. ${ }^{4}$ The NETT had a large enough subject enrollment to identify the subgroup of patients with emphysema with heterogeneous, upper lobe predominant disease, and low exercise capacity who have the best short- and long-term outcomes after bilateral LVRS, with significant improvements in survival and exercise capacity. The trial also identified that people with a forced expiratory volume in 1 second 


\section{Abbreviations and Acronyms \\ CMS $=$ Centers for Medicare \& Medicaid Services \\ $\mathrm{COPD}=$ chronic obstructive pulmonary disease \\ LVRS $=$ lung volume reduction surgery \\ NETT $=$ National Emphysema Treatment Trial \\ STS $=$ Society of Thoracic Surgeons}

of $20 \%$ or less than predicted and those with a homogeneous distribution of emphysema or carbon monoxide diffusing capacity of $20 \%$ or less than predicted were at high risk of death after LVRS. ${ }^{4}$ The NETT thus defined selection criteria for patients with emphysema who are appropriate candidates for LVRS by identifying those who are at high risk for poor outcomes. Since closure of the trial, multiple meta-analyses of LVRS outcomes have been performed using NETT data, but there have been few subsequent studies reporting LVRS outcomes in the post-NETT era. Approximately 10 years after the trial results were published, it is worthwhile to evaluate LVRS practice patterns and outcomes on a national level.

Despite the published benefits of LVRS as a treatment option for emphysema, the procedure is reportedly underused. ${ }^{10}$ Reasons for this are unclear, because COPD and emphysema comprise a significant burden of disease in the US population. The National Heart, Lung, and Blood Institute projected that COPD costs $\$ 29.6$ billion in direct healthcare expenditures and $\$ 20.4$ billion in indirect morbidity and mortality expenditures annually. ${ }^{11}$ In this study, we report on comprehensive LVRS data from the Society of Thoracic Surgeons (STS) Database beginning in 2003, when the NETT was first published. The STS Database provides a geographically diverse national sample, which unlike Medicare claims data, includes patients aged less than 65 years. This is a valuable advantage of STS data because approximately half of patients with emphysema in the country are aged 45 to 64 years. ${ }^{2}$ By examining the outcomes of LVRS in the STS Database and comparing outcomes with results of the NETT, our study assesses the performance of LVRS compared with the clinical benchmark set by a landmark clinical trial. This study has implications for future identification of determinants of LVRS quality and development of LVRS-specific quality benchmarks.

\section{MATERIALS AND METHODS \\ Study Design and Data Sources}

This study involved a retrospective review of de-identified aggregate statistics on patients who underwent LVRS reported in the STS Database from 2003 to 2011. Previously published data from the NETT ${ }^{4,5,12,13}$ were studied for statistical comparison. The University of Wisconsin Institutional Review Board approved this study.

\section{Study Populations}

Subjects in the NETT who were randomized to surgery underwent bilateral stapled wedge resection. These patients were subdivided into a non-high-risk group and a subgroup of non-high-risk patients with upper lobe predominant disease and low exercise tolerance.

Patients included in the analysis of patients in the STS Database underwent bilateral or unilateral resection. Both groups were included because of the lack of distinction between unilateral and bilateral LVRS in certain versions of the STS General Thoracic Surgery Database Major Procedure Collection Form. ${ }^{14}$ Patients with the following procedure codes were included:

Major Procedure Collection Form Version 2.2 (Last revised 2012): "Removal of lung, excision-plication of emphysematous lung(s) for lung volume reduction (LVRS) (32491)"; "Thoracoscopy with resectionplication for emphysematous lung (bullous or non-bullous) for lung volume reduction-LVRS, unilateral including any pleural procedure (32672)." Version 2.081 (Last revised 2009): "Removal of lung, excision-plication of emphysematous lung(s) for lung volume reduction (LVRS) (32491)." Versions 2.06 (2004) and 2.07 (2005): "Lung volume reduction."

\section{Analysis}

The STS Database yearly annual volume of LVRS was calculated to depict nationwide trends in volume over time, without attempt to capture total national volume. Meta-analysis was required to estimate differences between sample means and proportions using null hypothesis significance testing with $t$ tests and chi-square tests, respectively. This allowed for estimation of confidence intervals around calculated differences in event rates, while accounting for sample size. Confidence intervals around estimated differences were calculated using the $Z$ statistic, with alpha $=0.05$, assuming normal distribution. Preoperative and operative characteristics were compared between patients in the STS Database who underwent LVRS and patients in the NETT who were randomized to surgery. Preoperative characteristics included age, sex, race, and pulmonary function tests, which included percent of predicted forced expiratory volume in 1 second and carbon monoxide diffusing capacity. Operative characteristics accounted for the surgical approach to lung volume reduction: median sternotomy, video-assisted thoracoscopic surgery, or other.

Descriptive statistics on health status indicators and comorbidities of patients in the STS Database were calculated. Published data on the overall health status and comorbidities of subjects in the NETT were not directly comparable. Therefore, a descriptive comparison was made on the basis of related health indicators and NETT cohort selection criteria. STS health status indicators and comorbidities included congestive heart failure, coronary artery disease, pulmonary hypertension, systemic hypertension, peripheral vascular disease, diabetes, steroid use (defined as systemic steroid therapy, inhaled steroid therapy, or preoperative protocol within 30 days before the procedure), ${ }^{14}$ previous cardiothoracic surgery, lung cancer, smoking history, American Society of Anesthesiologists class, and Eastern Clinical Oncology Group/Zubrod score. Related health status indicators in the NETT included the Quality of Well-Being Score and the St George's Respiratory Questionnaire score; the Quality of Well-Being score, which ranges from 0 to 1 , with higher values indicating better health-related quality of life; ${ }^{15}$ and St George's Respiratory Questionnaire score, which ranges from 0 to 100 , with lower values indicating better health-related quality of life. ${ }^{16}$

Outcomes within 30 days of surgery were compared between patients in the STS Database and non-high-risk subjects in the NETT. These outcomes included readmission to the intensive care unit, sepsis, arrhythmia requiring treatment, myocardial infarction, ventilator dependence beyond 48 hours postoperatively, and reintubation. Mortality within 30 days of surgery was compared between patients in the STS Database and (1) all subjects in the NETT, (2) the non-high-risk NETT subset, and (3) the NETT subset with upper lobe predominant disease and low exercise tolerance. 


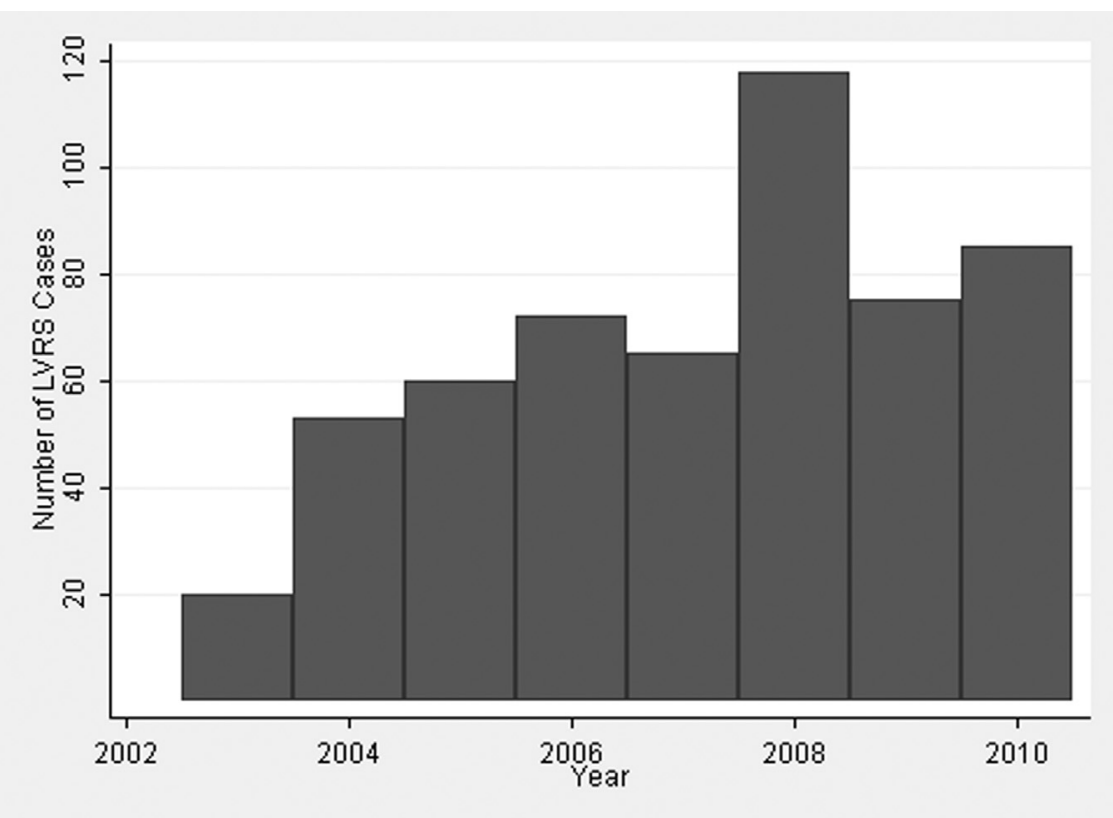

FIGURE 1. Yearly annual volume of LVRS reported in the STS Database from January 2003 to December 2010; 2011 volume is not shown, because yearly data were incomplete at the time of this study. LVRS, Lung volume reduction surgery.

In all analyses, missing observations in STS data were excluded from the denominator; however, patients with missing data were not excluded from the overall STS cohort. Only deidentified aggregate data were available from the STS Database; therefore, imputation could not be performed. Proportions of missing observations were reported with outcomes to aid interpretation. In addition, to account for missing data, mortality outcomes were analyzed under 2 other scenarios: one in which all missing patients were assumed to be alive and another in which all missing patients were assumed to be deceased. Statistical analyses were performed in STATA (StataCorp 2011. Stata Statistical Software: Release 12. StataCorp LP, College Station, Tex).

\section{RESULTS}

From January 2003 to June 2011, 585 patients underwent LVRS reported in the STS Database. The yearly annual volume of LVRS is shown in Figure 1. Patients in the STS Database were compared with the 608 NETT subjects who were randomized to surgery, of whom 538 were determined to be non-high risk and 139 had upper lobe predominant disease and low exercise tolerance.

When the preoperative characteristics of patients in the STS Database were compared with those of all NETT subjects, STS subjects were younger and a larger proportion was of a nonwhite race (Table 1). There were no patients in the STS Database with forced expiratory volume in $1 \mathrm{sec}-$ ond or carbon monoxide diffusing capacity less than $20 \%$ of predicted, who would fall into the high-risk category deemed by the NETT. Although the majority of NETT subjects underwent LVRS via a median sternotomy approach, most STS subjects underwent the procedure with a thoracoscopic approach. Other approaches included cervical, subxiphoid, thoracotomy, and transverse sternotomy.
Overall, less than half of patients in the STS Database had major comorbidities (Table 2). Approximately $10 \%$ of patients in the STS Database had previous cardiothoracic surgery, whereas NETT enrollees with previous sternotomy or lobectomy were excluded. Some $1.5 \%$ of patients in the STS Database had a diagnosis of lung cancer, whereas the

TABLE 1. Quantitative comparison of preoperative and operative characteristics of patients undergoing lung volume reduction surgery in the National Emphysema Treatment Trial versus the Society of Thoracic Surgeons Database

\begin{tabular}{|c|c|c|c|c|c|}
\hline \multirow[b]{2}{*}{ Characteristics } & \multirow{2}{*}{$\frac{\text { STS }}{\text { Mean }}$} & \multirow{2}{*}{$\frac{\text { NETT }}{\text { Mean }}$} & \multicolumn{2}{|c|}{ Mean difference } & \multirow[b]{2}{*}{$P$ value } \\
\hline & & & $\operatorname{Mean}|\boldsymbol{\Delta}|$ & $(95 \% \mathrm{CI})$ & \\
\hline Age, mean y & 61.3 & 66.5 & 5.2 & $(-6.1$ to -4.3$)$ & $<.001$ \\
\hline Sex & & & & & .192 \\
\hline Male & $54.6 \%$ & $58.4 \%$ & $3.7 \%$ & $(-9.4$ to 1.9$)$ & \\
\hline Female & $45.4 \%$ & $41.6 \%$ & $3.7 \%$ & $(-1.9$ to 9.4$)$ & \\
\hline Race & & & & & .010 \\
\hline White & $91.4 \%$ & $95.6 \%$ & $4.1 \%$ & $(-6.9$ to 9.7$)$ & \\
\hline Black & $5.1 \%$ & $3.1 \%$ & $1.9 \%$ & $(-0.3$ to 4.2$)$ & \\
\hline Other & $3.5 \%$ & $1.3 \%$ & $2.2 \%$ & $(0.4-3.9)$ & \\
\hline \multicolumn{6}{|l|}{ Pulmonary function tests } \\
\hline FEV1 \% predicted & $31.1 \%$ & $28.1 \%$ & $3.0 \%$ & $(1.6-4.4)$ & $<.001$ \\
\hline DLCO $\%$ predicted & $37.8 \%$ & $29.2 \%$ & $8.6 \%$ & $(6.9-10.2)$ & $<.001$ \\
\hline Surgical approach & & & & & $<.001$ \\
\hline Median sternotomy & $35.8 \%$ & $70.0 \%$ & $34.2 \%$ & $(-40.2$ to -28.1$)$ & \\
\hline VATS & $51.3 \%$ & $30.0 \%$ & $21.3 \%$ & $(15.1-27.5)$ & \\
\hline Other & $12.9 \%$ & $0 \%$ & $12.9 \%$ & $(9.6-16.3)$ & \\
\hline
\end{tabular}

CI, Confidence interval; DLCO, carbon monoxide diffusing capacity; FEVI, forced expiratory volume in 1 second; NETT, National Emphysema Treatment Trial; STS, Society of Thoracic Surgeons; VATS, video-assisted thoracic surgery. ${ }^{*} P$ values calculated using 2-sided $t$ tests for continuous variables and chi-square tests for differences in proportions. 
TABLE 2. Description of preoperative health status of patients undergoing lung volume reduction surgery in the Society of Thoracic Surgeons Database compared with the National Emphysema Treatment Trial selected cohort

\begin{tabular}{|c|c|c|}
\hline Patient characteristics & STS \% & NETT* $*$ \\
\hline \multicolumn{3}{|l|}{ Comorbidities } \\
\hline $\mathrm{CHF}$ & 2.6 & $\begin{array}{l}\text { Excluded if "Congestive heart failure within } 6 \text { mo of interview and ejection fraction } \\
\quad<45 \% \text { " }\end{array}$ \\
\hline Coronary artery disease & 17.4 & \\
\hline Pulmonary hypertension & 0.7 & $\begin{array}{l}\text { Excluded if "Pulmonary hypertension: mean } \mathrm{P}_{\mathrm{PA}} \text { on right heart catheterization } \geq 35 \\
\mathrm{~mm} \mathrm{Hg} \text { ( } \geq 38 \mathrm{~mm} \mathrm{Hg} \text { in Denver) or peak systolic } \mathrm{P}_{\mathrm{PA}} \text { on right heart } \\
\text { catheterization } \geq 45 \mathrm{~mm} \mathrm{Hg} \text { ( } \geq 50 \mathrm{~mm} \mathrm{Hg} \text { in Denver); right heart catheterization } \\
\text { is required to rule out pulmonary hypertension if peak systolic } \mathrm{P}_{\mathrm{PA}} \text { on } \\
\text { echocardiogram }>45 \mathrm{~mm} \mathrm{Hg} \text { " }\end{array}$ \\
\hline Systemic hypertension & 45.1 & $\begin{array}{l}\text { Excluded if "Uncontrolled hypertension (systolic > } 200 \text { mm Hg or diastolic >110 } \\
\text { mm Hg)" }\end{array}$ \\
\hline Peripheral vascular disease & 2.6 & \\
\hline Diabetes & 9.4 & \\
\hline Steroids & 17.8 & $\begin{array}{l}\text { Excluded if "Daily use of more than } 20 \mathrm{mg} \text { of prednisone or its equivalent as of } \\
\text { randomization" }\end{array}$ \\
\hline Previous cardiothoracic surgery & 9.9 & Excluded if "Previous sternotomy or lobectomy" \\
\hline Lung cancer & 1.5 & Excluded if "Evidence of systemic disease or neoplasia that is expected to \\
\hline Preoperative chemotherapy and radiation & 1.0 & $\begin{array}{l}\text { compromise survival over the duration of the trial" or "Pulmonary nodule } \\
\text { requiring surgery" }\end{array}$ \\
\hline Smoking history & & Included if "Nonsmoker (tobacco products) for 4 mo before initial interview and \\
\hline Current smoker & 4.6 & patient remains a nonsmoker throughout screening (by history)" \\
\hline Quit within 1 y previously & 8.4 & \\
\hline Quit $>1$ y ago & 52.5 & \\
\hline Never smoked & 34.5 & \\
\hline ASA class & & Surgical Patients' average daily Quality of Well-Being score: $\dagger$ \\
\hline I & 2.0 & $0.58 \pm 0.12$ \\
\hline II & 6.8 & Upper Lobe Predominant, Low Exercise Tolerant Quality of Well-Being score: \\
\hline III & 63.1 & $0.57 \pm 0.12$ \\
\hline IV & 28.0 & Surgical Patients' St George’s Respiratory Questionnaire Score: $\ddagger$ \\
\hline $\mathrm{V}$ & 0.2 & $52.5 \pm 12.6$ \\
\hline ECOG/Zubrod score & & Upper Lobe Predominant, Low Exercise Tolerant St George's Respiratory \\
\hline 0, normal activity & 9.1 & Questionnaire Score: \\
\hline 1 , symptomatic but ambulatory & 63.1 & $54.3 \pm 12.1$ \\
\hline 2 , symptomatic, $<50 \%$ daytime in bed & 20.4 & \\
\hline 3 , symptomatic, $>50 \%<100 \%$ daytime in bed & 4.5 & \\
\hline 4 , bedridden & 2.9 & \\
\hline
\end{tabular}

ASA, American Society of Anesthesiologists; ECOG, Eastern Clinical Oncology Group; $C H F$, congestive heart failure; $N E T T$, National Emphysema Treatment Trial; STS, Society of Thoracic Surgeons; $P_{P A}$, pulmonary arterial pressure. *Referenced from Fishman and colleagues ${ }^{4}$ (Appendix Table E1). $\dagger$ Quality of Well-Being score is on a scale from 0 to 1 , with higher scores indicating better health. $\ddagger$ St George’s Respiratory Questionnaire score is on a scale from 0 to 100 , with lower scores indicating better health.

NETT excluded enrollees with pulmonary nodules or evidence of neoplasia that could interfere with the trial.

The majority of patients in the STS Database had American Society of Anesthesiologists class III or IV and Eastern Clinical Oncology Group or Zubrod scores of 1 or 2 , indicating that most patients were symptomatic and ambulatory or partially disabled. This parallels with the middle-range health-related quality of life scores reported by NETT subjects (Table 2).

The median time from surgery to evaluation of 30-day outcomes was 0.7 month in all NETT subjects, including the non-high-risk subset and 0.8 month in the subset with upper lobe predominant disease and low exercise tolerance. ${ }^{4}$ Outcomes were assessed at 30 days postoperatively in the STS Database. Given the slight difference in time from surgery to evaluation of outcomes in NETT versus the STS Database, mortality within 60 days is reported for NETT subjects as a frame of reference.

Mortality within 30 days of LVRS was not significantly different between STS subjects and all NETT subjects (Table 3). When 30-day mortality rates were compared between STS subjects and the non-high-risk NETT subset (Table 4), as well as the NETT subset with upper lobe predominant disease and low exercise tolerance (Table 5), STS subjects had a $3 \%$ to $4 \%$ higher mortality rate that was statistically significant. Mortality assessed at 1.7 months postoperatively was $4.8 \%$ among non-high-risk NETT subjects and $2.9 \%$ among subjects with upper lobe 
TABLE 3. Comparison of outcomes after lung volume reduction surgery in Society of Thoracic Surgeons Database versus National Emphysema Treatment Trial

\begin{tabular}{|c|c|c|c|c|c|}
\hline \multirow[b]{2}{*}{ Outcomes } & \multirow[b]{2}{*}{ STS* \% } & \multirow[b]{2}{*}{ All NETT \% } & \multicolumn{2}{|c|}{ Difference } & \multirow[b]{2}{*}{$\boldsymbol{P}$ value } \\
\hline & & & $\%|\boldsymbol{\Delta}|$ & $(95 \%$ CI $)$ & \\
\hline 30-d mortality & 5.6 & 3.6 & 2.0 & $(-0.5$ to 4.5$)$ & .113 \\
\hline
\end{tabular}

predominant disease and low exercise tolerance, compared with the STS 30-day mortality rate of 5.6\%.

When other outcomes were compared between STS subjects and non-high-risk NETT subjects randomized to surgery, there were no significant differences in rates of intensive care unit readmission, sepsis, arrhythmia requiring treatment, or myocardial infarction (Table 4). STS subjects had significantly lower rates of ventilator dependence lasting more than 48 hours postoperatively and reintubation.

Mortality data were missing for $83(14 \%)$ of the patients in the STS Database. There were 213 to 214 (36\%-37\%) missing observations for each of the other outcome variables; missing observations were excluded from sample proportions. When all missing patients were assumed to be alive, rather than excluded, no significant differences in mortality were identified between patients undergoing LVRS in the STS Database versus the NETT (Appendix Tables E1 and E2). Mortality rates were significantly higher for patients undergoing LVRS in the STS Database compared with those in the NETT when all missing patients were assumed to be deceased (Appendix Tables $\mathrm{E} 3$ and E4).

\section{DISCUSSION}

This study of LVRS in the STS Database from 2003 to 2011 is the first longitudinal, population-level assessment

TABLE 4. Comparison of outcomes after lung volume reduction surgery in Society of Thoracic Surgeons Database versus non-highrisk National Emphysema Treatment Trial subset

\begin{tabular}{|c|c|c|c|c|c|}
\hline \multirow[b]{2}{*}{ Outcomes } & \multirow[b]{2}{*}{ STS $* \%$} & \multirow{2}{*}{$\begin{array}{c}\text { Non-high-risk } \\
\text { NETT subset } \%\end{array}$} & \multicolumn{2}{|r|}{ Difference } & \multirow[b]{2}{*}{$\boldsymbol{P}$ value $\dagger$} \\
\hline & & & $\%|\boldsymbol{\Delta}|$ & $(95 \% \mathrm{CI})$ & \\
\hline 30-d mortality $\ddagger$ & 5.6 & 2.2 & 3.4 & $(1.0-5.0)$ & .005 \\
\hline $\begin{array}{l}\text { Readmittance } \\
\quad \text { to } \mathrm{ICU}_{\S}\end{array}$ & 7.8 & 11.7 & 3.9 & $(-8.8$ to 1.0$)$ & .156 \\
\hline Sepsis $\S$ & 1.9 & 2.5 & 0.6 & $(-2.5$ to 1.3$)$ & .544 \\
\hline Arrhythmia $\S$ & 16.2 & 18.6 & 2.4 & $(-7.5$ to 2.6$)$ & .350 \\
\hline MI $\S$ & 1.1 & 1.0 & 0.1 & $(-1.3$ to 1.4$)$ & .910 \\
\hline Ventilator $>48 \mathrm{~h} \S$ & 4.6 & 13.6 & 9.1 & $(-12.7$ to -5.4$)$ & $<.001$ \\
\hline Reintubation $\S$ & 12.9 & 21.8 & 8.9 & $(-13.8$ to -3.9$)$ & $<.001$ \\
\hline
\end{tabular}

CI, Confidence interval; $I C U$, intensive care unit; $M I$, myocardial infarction; NETT, National Emphysema Treatment Trial; STS, Society of Thoracic Surgeons. *Missing STS observations excluded. $\dagger P$ values from chi-square tests. $\ddagger$ Referenced from Fishman and colleagues. ${ }^{4} \S$ Referenced from Naunheim and colleagues. ${ }^{13}$
TABLE 5. Comparison of outcomes after lung volume reduction surgery in Society of Thoracic Surgeons Database versus National Emphysema Treatment Trial subset with upper-lobe predominant disease and low exercise tolerance

\begin{tabular}{|c|c|c|c|c|c|}
\hline \multirow[b]{2}{*}{ Outcomes } & \multirow[b]{2}{*}{ STS* \% } & \multirow{2}{*}{$\begin{array}{c}\text { NETT, upper } \\
\text { lobe disease } \downarrow \text { exercise } \\
\text { tolerance } \%\end{array}$} & \multicolumn{2}{|c|}{ Difference } & \multirow[b]{2}{*}{$\boldsymbol{P}$ value $\nmid$} \\
\hline & & & $\%|\boldsymbol{\Delta}|$ & $(95 \% \mathrm{CI})$ & \\
\hline 30-d mortality $\ddagger$ & 5.6 & 1.4 & 4.2 & $(1.4-7.0)$ & .039 \\
\hline
\end{tabular}

of LVRS since the NETT. Our study demonstrates that since the NETT was published in 2003, surgeons have performed LVRS for a broader group of patients (including smokers, younger patients, and people with previous cardiac surgery); techniques have evolved (with greater use of thoracoscopic surgery); and outcomes differ in some areas while remaining the same in others.

The annual volume of LVRS in the STS Database increased substantially from 2003 to 2004 but did not steadily increase thereafter. This suggests that LVRS is underused, as reported in a study of Medicare claims from 2004 to 2005 in which there were only 258 claims for LVRS over 21 months. $^{10}$ When considering that emphysema is reported to affect 4.7 million Americans, ${ }^{2}$ it appears that only a small proportion of these patients are pursuing LVRS as a treatment option. Reasons for this remain unclear. Overly restrictive patient selection criteria do not appear to be the cause. Overall differences in patient characteristics between the STS Database and the NETT demonstrate that patient selection was less restrictive in the STS Database. With underuse unlikely to be related to restrictive selection criteria, it may instead be related to restrictive referral patterns and limited access to this specialized surgery.

When compared with subjects in the NETT, more subjects in the STS Database underwent LVRS via a thoracoscopic approach, which is likely a consequence of an increase in surgeons' comfort with thoracoscopy and video-assisted thoracoscopic surgery. ${ }^{17}$ The fact that $10 \%$ of patients in the STS Database had previous cardiothoracic surgery is a testament to surgeons' increased comfort with the technical aspects of the lung volume reduction procedure. The younger mean age of STS subjects may relate to increasing numbers of insurers offering coverage of LVRS, ${ }^{18,19}$ following the Centers for Medicare \& Medicaid Services (CMS) published criteria for expanded coverage of LVRS in 2003. ${ }^{20}$ However, the CMS has restricted the types of facilities that are eligible for reimbursement of LVRS to those approved for the NETT, credentialed by the Joint Commission on Accreditation of Healthcare Organizations under their Disease Specific Certification Program for LVRS, and those approved by Medicare for lung or heart and lung transplants. ${ }^{21}$ Although this 
policy maintains the quality of LVRS by requiring that the appropriate infrastructure is in place, it likely restricts access to this surgery that could benefit more than 1 million Americans. To address underuse of LVRS, perhaps an increase in the number of healthcare teams dedicated to treatment of advanced pulmonary disease is needed, similar to but distinct from healthcare teams dedicated to heart and lung transplantation or thoracic oncology.

In this study, $1.5 \%$ of patients in the STS Database were reported to have lung cancer. This may have been a result of miscoding of the surgical procedure as a lung volume reduction rather than a cancer resection, but the surgery also may have been performed for the dual purpose of lung volume reduction and cancer resection, as previously published. ${ }^{22}$ Coding errors are always possible when collecting administrative data. However, given the stringent reporting requirements for reimbursement of LVRS, ${ }^{18-21}$ there is a low likelihood that coding errors would be frequent enough to skew the results in our large sample size of more than 500 patients.

Outcomes after LVRS were similar between the STS Database and the NETT, with key exceptions. Lower rates of reintubation and prolonged ventilation in the STS Database may be related to nationwide efforts to improve these outcomes over the past decade. The STS, the American College of Surgeons-National Surgical Quality Improvement Program, ${ }^{23}$ and the Physician Quality Reporting System in conjunction with $\mathrm{CMS}^{24}$ use reintubation and prolonged ventilation as healthcare quality indicators. Hospitals throughout the country have developed qualityimprovement programs to address these indicators, with increasing success. ${ }^{25,26}$

Analysis of outcomes further demonstrated that patients in the STS Database had a similar 30-day mortality rate when compared with all NETT subjects, but when compared with non-high-risk NETT subjects and those with upper lobe predominant disease and low exercise tolerance, STS subjects had a higher mortality rate. This may be related to differences in patient selection or surgical care outside of a clinical trial. Given that 30-day mortality has been demonstrated to be higher in patients undergoing bilateral resection, compared with unilateral resection, ${ }^{27}$ the inclusion of patients in the STS Database who underwent unilateral LVRS was expected to have skewed the 30-day mortality rate in the STS Database to a rate lower than reported in the NETT; however, this was not the case.

As public attention to quality reporting increases and pay-for-performance policies are increasingly implemented, thoracic surgeons may be compelled to decide on thresholds for mortality. It may be unreasonable to expect the outcomes in practice to be as good as the best subgroup of outcomes in a randomized controlled clinical trial, but it is reasonable to expect a certain standard of care and decide on a threshold at which mortality risk cannot outweigh potential benefits.

This study measured outcomes with respect to an absolute benchmark set by the NETT. Current pay-forperformance models are based on both absolute and relative performance measurements. ${ }^{28}$ Therefore, future investigation of relative performance measurements for LVRS would allow hospitals to compare their performance with others and potentially learn from high-performing outliers' patient selection, follow-up care, and other potential determinants of quality.

Although the less-restrictive patient selection demonstrated in the STS cohort may contribute to the higher mortality rate when compared with the selected NETT subjects, a small difference in mortality rates may not warrant restricting marginal non-high-risk candidates from access to this potentially life-saving procedure that has been shown to provide substantial improvements in quality of life..$^{4-9}$

\section{Study Limitations}

It is worth mentioning that the mortality rates reported in the NETT were captured under a slightly narrower time window (0.7 month in all NETT subjects including the non-high-risk subset and 0.8 month in the upper lobe predominant low exercise tolerant subset) compared with the 30-day mortality in the STS Database. Given that the non-high-risk NETT subset mortality rates at 1.7 months remained below the STS 30-day mortality rate, it is unlikely that the $3 \%$ to $4 \%$ difference in mortality rates can be wholly attributed to the difference in time windows. Although there were differences in data collection between the STS Database and the NETT, as described, comparison remains informative with this limitation in mind.

This study also was limited by a lack of long-term data on outcomes of patients in the STS Database. Although 30-day outcomes were useful for assessing quality of care in the short term, previous studies have shown that the measurement of survival benefits and improvement in quality-adjusted life after LVRS requires long-term data collection. ${ }^{5,9}$ Measurement of 90-day and 1-year outcomes after LVRS in quality-assessment databases such as that of the STS would facilitate future studies. This study of the STS Database also was limited by missing data, which comprised $14 \%$ to $37 \%$ of observations. Results should be interpreted while considering the proportion of missing observations (Appendix Table E1). Overall, the limitations of this study were largely due to limitations of observational data. The STS Database provides a national sample that is likely to be biased toward higher participation by major academic centers and hospitals with sufficient data-collection resources. This study was not designed to capture total national LVRS volume in the United States or to prescribe policy to address LVRS quality. Rather, the study was designed to provide a description that facilitates further investigation 
into quality assessment and quality assurance for LVRS. As we have demonstrated, this goal was achieved, and the STS Database proved to be useful in providing an unadjusted assessment of volume and outcomes for LVRS.

Keeping thoracic surgeons apprised of unadjusted quality assessments is essential to involving surgeons in the identification of surgery-specific determinants of quality, the development of surgery-specific quality measures, and therefore the evolution of quality-improvement databases such as that of the STS. This study highlights the need to invest in future analyses that identify determinants of outcomes after LVRS so that future quality assessments can adjust for patient characteristics, payer status, location, and so forth. This is an iterative process that is best conducted with surgeons' involvement.

\section{CONCLUSIONS}

Overall, the major findings of this study demonstrate that mortality rates are higher in the STS Database than they were in selected NETT subjects and about the same compared with the overall NETT LVRS arm. Interpretation of differences in mortality rates is complicated by lack of consensus on appropriate benchmarks for mortality rates after LVRS. Our results and conclusions, like those of any observational study, are limited to description and interpretation of the available data. We maintain that the STS Database provides a geographically diverse national sample of outcomes after LVRS that may capture national trends. This study demonstrates the importance of patient selection and the need to develop consensus on appropriate benchmarks for morbidity and mortality rates after LVRS. Our study also underscores the need for primary care providers, pulmonologists, and thoracic surgeons to address the heavy burden of chronic lower respiratory disease in the United States by more frequently engaging a multidisciplinary team in discussions with patients regarding the treatment options for emphysema, taking into consideration individual patient risk factors and weighing risks and benefits in an evidence-based fashion. More dedicated centers for treatment of advanced respiratory disease are needed to improve access to LVRS, while refining preoperative evaluation and postoperative management of emphysema in a coordinated way.

\section{References}

1. Kochanek KD, Xu J, Murphy SL, Miniño AM, Kung H. National vital statistics reports. Natl Vital Stat Rep. 2011;59:1.

2. Brown DW, Croft JB, Greenlund KJ, Giles WH. Deaths from chronic obstructive pulmonary disease-United States, 2000-2005. MMWR Morb Mortal Wkly Rep. 2008:57:1229-32.

3. American Lung Association. Trends in COPD (emphysema and chronic bronchitis): morbidity and mortality. February 2010. Available at: http://www. lungusa.org/finding-cures/our-research/trend-reports/copd-trend-report.pdf. Accessed April 12, 2013.

4. Fishman A, Martinez F, Naunheim K, Piantadosi S, Wise R, Ries A, et al. A randomized trial comparing lung-volume-reduction surgery with medical therapy for severe emphysema. N Engl J Med. 2003;348:2059-73.
5. Naunheim KS, Wood DE, Mohsenifar Z, Sternberg AL, Criner GJ, DeCamp MM, et al. Long-term follow-up of patients receiving lung-volume-reduction surgery versus medical therapy for severe emphysema by the National Emphysema Treatment Trial Research Group. Ann Thorac Surg. 2006;82:431.

6. Geddes D, Davies M, Koyama H, Hansell D, Pastorino U, Pepper J, et al. Effect of lung-volume-reduction surgery in patients with severe emphysema. $N$ Engl J Med. 2000;343:239-45

7. Goldstein RS, Todd TR, Guyatt G, Keshavjee S, Dolmage TE, van Rooy S, et al. Influence of lung volume reduction surgery (LVRS) on health related quality of life in patients with chronic obstructive pulmonary disease. Thorax. 2003;58: 405-10.

8. Hillerdal G, Lofdahl CG, Strom K, Skoogh BE, Jorfeldt L, Nilsson F, et al. Comparison of lung volume reduction surgery and physical training on health status and physiologic outcomes: a randomized controlled clinical trial. Chest. 2005;128:3489-99.

9. Miller JD, Malthaner RA, Goldsmith CH, Goeree R, Higgins D, Cox PG, et al. A randomized clinical trial of lung volume reduction surgery versus best medica care for patients with advanced emphysema: a two-year study from Canada. Discussion. Ann Thorac Surg. 2006;81:314-21.

10. Ramsey SD, Shroyer AL, Sullivan SD, Wood DE. Updated evaluation of the cost effectiveness of lung volume reduction surgery. Chest. 2007;131:823-32.

11. National Heart Lung and Blood Institute. Morbidity and Mortality: 2009 Chart Book on Cardiovascular, Lung and Blood Diseases. Available at: http://www. nhlbi.nih.gov/resources/docs/2009_ChartBook.pdf. Accessed May 31, 2013.

12. DeCamp MM, Blackstone EH, Naunheim KS, Krasna MJ, Wood DE, Meli YM et al. Patient and surgical factors influencing air leak after lung volume reduction surgery: lessons learned from the National Emphysema Treatment Trial. Ann Thorac Surg. 2006;82:197.

13. Naunheim KS, Wood DE, Krasna MJ, DeCamp MM Jr, Ginsburg ME, McKenna RJ Jr, et al. Predictors of operative mortality and cardiopulmonary morbidity in the National Emphysema Treatment Trial. J Thorac Cardiovasc Surg. 2006;131:43-53.

14. Society of Thoracic Surgeons. STS General Thoracic Database, Data Collection Forms. Available at: http://www.sts.org/quality-research-patient-safety/nationaldatabase/database-managers/general-thoracic-surgery-databa-1. Accessed October $1,2013$.

15. Kaplan RM, Atkins CJ, Timms R. Validity of a quality of well-being scale as an outcome measure in chronic obstructive pulmonary disease. J Chronic Dis. 1984; 37:85-95.

16. Jones PW, Quirk FH, Baveystock CM, Littlejohns P. A self-complete measure of health status for chronic airflow limitation: the St. George's Respiratory Questionnaire. Am Rev Respir Dis. 1992;145:1321-7.

17. Boffa DJ, Gangadharan S, Kent M, Kerendi F, Onaitis M, Verrier E, et al Self-perceived video-assisted thoracic surgery lobectomy proficiency by recent graduates of North American thoracic residencies. Interact Cardiovasc Thorac Surg. 2012;14:797-800.

18. Blue Cross Blue Shield Association policy \# 7.01.71. Available at: http://www bcbsms.com/index.php?q=provider-medical-policy-search.html\&action=view Policy\&path=\%2Fpolicy \%2Femed\%2FLung_Volume_Reduction_Surgery.html. Accessed May 31, 2013.

19. Aetna. Clinical Policy Bulletin: Lung Volume Reduction Surgery. Number: 0160 Available at: http://www.aetna.com/cpb/medical/data/100_199/0160.html. Accessed May 31, 2013.

20. Medicare National Coverage Determinations. Chapter 1, Part 4 (Sections 200-310.1), Rev. 62. Section 240.1-lung volume reduction surgery. In: CMS Manual System. Washington, DC: Department of Health and Human Services.

21. Centers for Medicare \& Medicaid Services. Lung Volume Reduction Surgery. Available at: http://www.cms.gov/Medicare/Medicare-GeneralInformation/MedicareApprovedFacilitie/Lung-Volume-Reduction-Surgery-LVRS html. Accessed April 22, 2013.

22. Choong CK, Meyers BF, Battafarano RJ, Guthrie TJ, Davis GE, Patterson GA, et al. Lung cancer resection combined with lung volume reduction in patients with severe emphysema. J Thorac Cardiovasc Surg. 2004;127:1323-31.

23. American College of Surgeons. American College of Surgeons National Surgical Quality Improvement Program (ACS NSQIP). Available at: http://site.acsnsqip. org. Accessed April 12, 2013.

24. Centers for Medicare and Medicaid Services. Physician Quality Reporting System. Available at: http://www.cms.gov/Medicare/Quality-Initiatives-Patient-Asse ssment-Instruments/PQRS/index.html?redirect=/PQRS/. Accessed April 12, 2013

25. Robertson TE, Sona C, Schallom L, Buckles M, Cracchiolo L, Schuerer D, et al Improved extubation rates and earlier liberation from mechanical ventilation 
with implementation of a daily spontaneous-breathing trial protocol. J Am Coll Surg. 2008;206:489-95.

26. Cohen J, Shapiro M, Grozovski E, Fox B, Lev S, Singer P. Prediction of extubation outcome: a randomised, controlled trial with automatic tube compensation vs. pressure support ventilation. Crit Care. 2009;13:R21.
27. Kotloff RM, Tino G, Palevsky HI, Hansen-Flaschen J, Wahl PM, Kaiser LR, et al Comparison of short-term functional outcomes following unilateral and bilateral lung volume reduction surgery. Chest. 1998;113:890-5.

28. Eijkenaar F. Key issues in the design of pay for performance programs. Eur J Health Econ. 2013;14:117-31.

Access to The Journal of Thoracic and Cardiovascular Surgery Online is reserved for print subscribers!

Full-text access to The Journal of Thoracic and Cardiovascular Surgery Online is available for all print subscribers. To activate your individual online subscription, please visit The Journal of Thoracic and Cardiovascular Surgery Online, point your browser to http://www.mosby.com/itcvs, follow the prompts to activate your online access, and follow the instructions. To activate your account, you will need your subscriber account number, which you can find on your mailing label (note: the number of digits in your subscriber account number varies from 6 to 10 ). See the example below in which the subscriber account number has been circled:

\section{Sample mailing label}

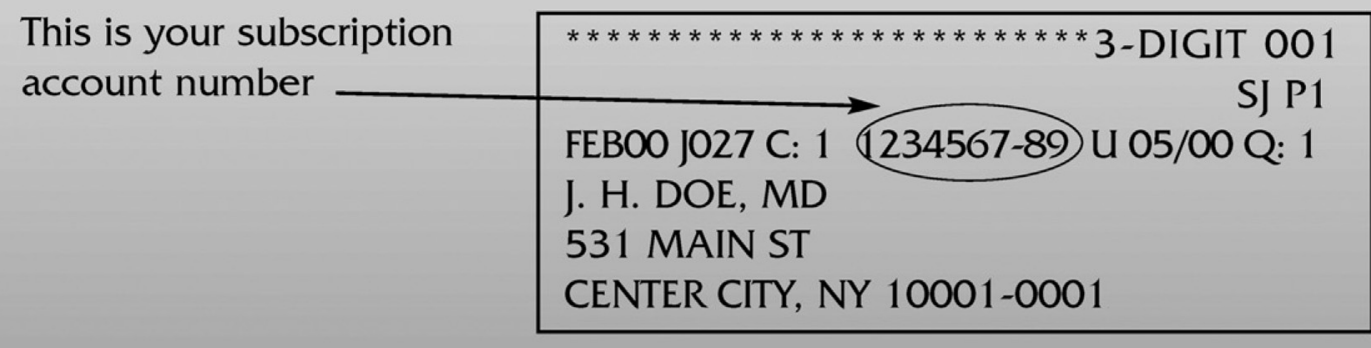

Personal subscriptions to The Journal of Thoracic and Cardiovascular Surgery Online are for individual use only and may not be transferred. Use of The Journal of Thoracic and Cardiovascular Surgery Online is subject to agreement to the terms and conditions as indicated online. 
APPENDIX TABLE E1. Comparison of outcomes after lung volume reduction surgery in Society of Thoracic Surgeons Database versus National Emphysema Treatment Trial: Missing patients in the Society of Thoracic Surgeons Database assumed to be alive

\begin{tabular}{|c|c|c|c|c|c|}
\hline \multirow[b]{2}{*}{ Outcomes } & \multirow[b]{2}{*}{ STS $* \%$} & \multirow[b]{2}{*}{ All NETT \% } & \multicolumn{2}{|c|}{ Difference } & \multirow[b]{2}{*}{$P$ value } \\
\hline & & & $\%|\boldsymbol{\Delta}|$ & $(95 \%$ CI $)$ & \\
\hline 30-d mortality & 4.8 & 3.6 & 1.2 & $(-0.1$ to 3.5$)$ & .306 \\
\hline
\end{tabular}

APPENDIX TABLE E3. Comparison of outcomes after lung volume reduction surgery in Society of Thoracic Surgeons Database versus National Emphysema Treatment Trial: Missing Society of Thoracic Surgeons subjects assumed to be deceased

\begin{tabular}{|c|c|c|c|c|c|}
\hline \multirow[b]{2}{*}{ Outcomes } & \multirow[b]{2}{*}{ STS* \% } & \multirow[b]{2}{*}{ All NETT \% } & \multicolumn{2}{|c|}{ Difference } & \multirow[b]{2}{*}{$P$ value } \\
\hline & & & $\%|\boldsymbol{\Delta}|$ & $(95 \%$ CI $)$ & \\
\hline 30-d mortality & 19.0 & 3.6 & 15.4 & $(11.9-18.9)$ & $<.001$ \\
\hline
\end{tabular}

APPENDIX TABLE E4. Comparison of outcomes after lung volume reduction surgery in Society of Thoracic Surgeons Database versus National Emphysema Treatment Trial subjects with upper-lobe predominant disease and low exercise tolerance: Missing Society of Thoracic Surgeons subjects assumed to be deceased

\begin{tabular}{|c|c|c|c|c|c|}
\hline \multirow[b]{2}{*}{ Outcomes } & \multirow[b]{2}{*}{ STS* \% } & \multirow{2}{*}{$\begin{array}{c}\text { NETT, upper } \\
\text { lobe disease } \downarrow \text { exercise } \\
\text { tolerance } \% \\
\end{array}$} & \multicolumn{2}{|c|}{ Difference } & \multirow[b]{2}{*}{$P$ value } \\
\hline & & & $\%|\boldsymbol{\Delta}|$ & $(95 \% \mathrm{CI})$ & \\
\hline 30-d mortality & 19.0 & 1.4 & 17.6 & $(13.8-21.3)$ & $<.001$ \\
\hline
\end{tabular}

\author{
square tests. $\ddagger$ Referenced from Fishman and colleagues. ${ }^{4}$
}

APPENDIX TABLE E2. Comparison of outcomes after lung volume reduction surgery in Society of Thoracic Surgeons Database versus National Emphysema Treatment Trial subjects with upper-lobe predominant disease and low exercise tolerance: Missing Society of Thoracic Surgeons subjects assumed to be alive

\begin{tabular}{|c|c|c|c|c|c|}
\hline \multirow[b]{2}{*}{ Outcomes } & \multirow[b]{2}{*}{ STS* \% } & \multirow{2}{*}{$\begin{array}{c}\text { NETT, upper } \\
\text { lobe disease } \downarrow \text { exercise } \\
\text { tolerance } \%\end{array}$} & \multicolumn{2}{|c|}{ Difference } & \multirow[b]{2}{*}{$\boldsymbol{P}$ value $\dagger$} \\
\hline & & & $\%|\boldsymbol{\Delta}|$ & $(95 \% \mathrm{CI})$ & \\
\hline 30-d mortality $\ddagger$ & 4.8 & 1.4 & 3.4 & $(0.8-6.0)$ & .072 \\
\hline
\end{tabular}

